\title{
Bile Acid Metabolism. I. Studies on the Mechanisms of Intestinal Transport*
}

\author{
John M. Dietschy, $†$ Herbert S. Salomon, and Marvin D. Siperstein $\ddagger$ \\ (From the Department of Internal Medicine, The University of Texas Southwestern Medical \\ School, Dallas, Texas)
}

Bile acids, the products of oxidative catabolism of cholesterol by the liver, play an important role in the intestinal absorption of fat. Recent work suggests that these amphipathic sterols act not only as simple emulsifying agents but, more importantly, also as the basic micellar structure into which the poorly soluble amphiphylic monoglycerides and long chain fatty acids become solubilized (1). It is largely as a consequence of the formation of these "mixed micelles" that absorption of fat into the mucosal cells of the gastrointestinal tract is facilitated.

It has been appreciated for many years that bile acids undergo an enterohepatic circulation with absorption from the gastrointestinal tract followed by rapid clearance from the blood as the liver secretes these acid sterols back into the bile. The intestinal absorptive phase of this cycle is of considerable theoretical as well as clinical interest, since an understanding of the transport mechanisms whereby bile acids normally are able to penetrate the mucosal cell barrier no doubt will be necessary before the elucidation of the pathophysiology of certain malabsorption syndromes associated with deranged bile acid metabolism is possible. Yet, despite the potential physiologic importance of bile acid absorption, little detailed data are currently available concerning the transport of these sterols. For example, several studies have shown that the ileum is capable of moving conjugated and unconjugated bile acids against a

* Submitted for publication August 19, 1965 ; accepted February 15, 1966.

This study was supported by U. S. Public Health Service grants CA- 05801 and CA- 05090 and by a grant from the Damon Runyon Memorial Fund.

† Postdoctoral fellow, National Institute of Arthritis and Metabolic Diseases.

$\ddagger$ Research Career Awardee, National Heart Institute. Address requests for reprints to Dr. M. D. Siperstein, Dept. of Internal Medicine, University of Texas Southwestern Medical School, Dallas, Texas 75235. concentration gradient (2-5). Although previously measured values for the transmural potential difference would suggest that such movement, at least in the case of conjugated bile salts, involves active transport, such a process has not been precisely identified under conditions of controlled electrochemical potential gradients across the intestinal wall. Furthermore, no quantification has been made of the relative physiologic importance of passive transport phenomena that may allow the net movement of bile acid down the activity gradient normally present between the intestinal contents and the vascular space. And, finally, no assessment of the effect of bulk water movement upon bile acid movement has yet been published.

The present investigation was therefore undertaken to precisely identify both the active and passive transport mechanisms that result in the net movement of conjugated and unconjugated bile salts from the intestinal lumen into the blood. Four specific processes were defined: 1) Determination of bidirectional fluxes under conditions of a zero electrochemical potential gradient across the intestinal wall clearly established that in the distal half of the small bowel there exists an active transport process that does not discriminate between conjugated and unconjugated bile acids. 2) The passive ionic diffusion of conjugated and unconjugated bile salts was demonstrated to occur down an activity gradient at essentially equal rates for both kinds of bile salts at all levels of the small bowel. 3) By altering the $\mathrm{pH}$ conditions to favor the formation of un-ionized bile acids, it was shown that the passive nonionic diffusion of this chemical species across the intestinal mucosa occurred at six to seven times the rate found for the movement of ionized bile salts. 4) Finally, solvent drag produced a slight but definite effect upon the passive movement of bile acids. These processes were examined under both in vitro and 
in vivo conditions, and their relative importance to bile acid absorption was established.

\section{Methods \\ Reagents}

Cholic acid ${ }^{1}$ was purified by recrystallization twice from ethyl acetate and was shown on thin layer chromatography to be $>98 \%$ cholic acid (6). Taurocholic acid $^{2}$ was purified by chromatography on thin layer plates (6) followed by precipitation from ethanol. On rechromatography $98 \%$ of the purified material traveled in the taurocholic acid area. Cholic-carboxyl- ${ }^{14} \mathrm{C}$ acid ${ }^{3}$ of $99 \%$ purity was obtained by thin layer chromatography. Taurocholic-carboxyl- ${ }^{14} \mathrm{C}$ acid was synthesized biologically by the injection of cholic acid- ${ }^{14} \mathrm{C}$ intravenously into a rat prepared with a biliary fistula and was likewise purified by thin layer chromatography (6).

\section{Solutions}

The basic perfusion solution in in vitro experiments was Krebs bicarbonate buffer (7). In particular experiments in which alteration in $\mathrm{pH}$ from 7.4 was desired, a $100 \mathrm{mM}$ solution of either Tris-[2-amino-2-(hydroxymethyl)-1,3-propanediol] (for $\mathrm{pH}>7.4$ ) or of dibasic sodium phosphate (for $\mathrm{pH}<7.4$ ) was utilized. Both of these solutions were made isosmotic by the addition of mannitol. $\mathrm{pH}$ adjustments were always made at $37^{\circ} \mathrm{C}$ with the solution constantly in equilibrium with a $95 \%$ oxygen: $5 \%$ carbon dioxide mixture by the addition of either $90 \% \mathrm{NaOH}$ or concentrated $\mathrm{HCl}$.

\section{Tissue preparations}

Only 180 - to $220-\mathrm{g}$ female Sprague-Dawley rats fed ad libitum were used in these experiments. For purposes of identification the entire small intestine was divided into ten segments of equal length and numbered from 1 to 10 . Thus, segment 1 contained the distal duodenum and most proximal jejunum, segments 2 through 5 were from the remaining jejunum, and segments 6 through 10 were from the ileum. Three different types of experimental preparations were used in these studies.

1) Everted intestinal sacs. Everted gut sacs were prepared from each of the ten segments according to the method of Wilson and Wiseman (8). The volume of the serosal and mucosal solutions was $1.0 \mathrm{ml}$ and $10.0 \mathrm{ml}$, respectively. The incubation flasks were gassed with 95\% oxygen : $5 \%$ carbon dioxide, capped, and incubated in a metabolic shaker at $37^{\circ} \mathrm{C}$ for 90 minutes. After the incubation period, the serosal and mucosal solutions were immediately separated, and the bile salt concentration (9) and ${ }^{14} \mathrm{C}$ content were determined.

2) In vitro perfusion system. The intestinal perfusion apparatus shown diagrammatically in Figure 1 was used in these studies. A $10-\mathrm{cm}$ segment of small intestine was everted on a glass rod, then mounted on the central glass

\footnotetext{
1 Eastman Organic Chemicals, Rochester, N. Y.

2 Nutritional Biochemicals Corp., Cleveland, Ohio.

3 New England Nuclear Corp., Boston, Mass.
}

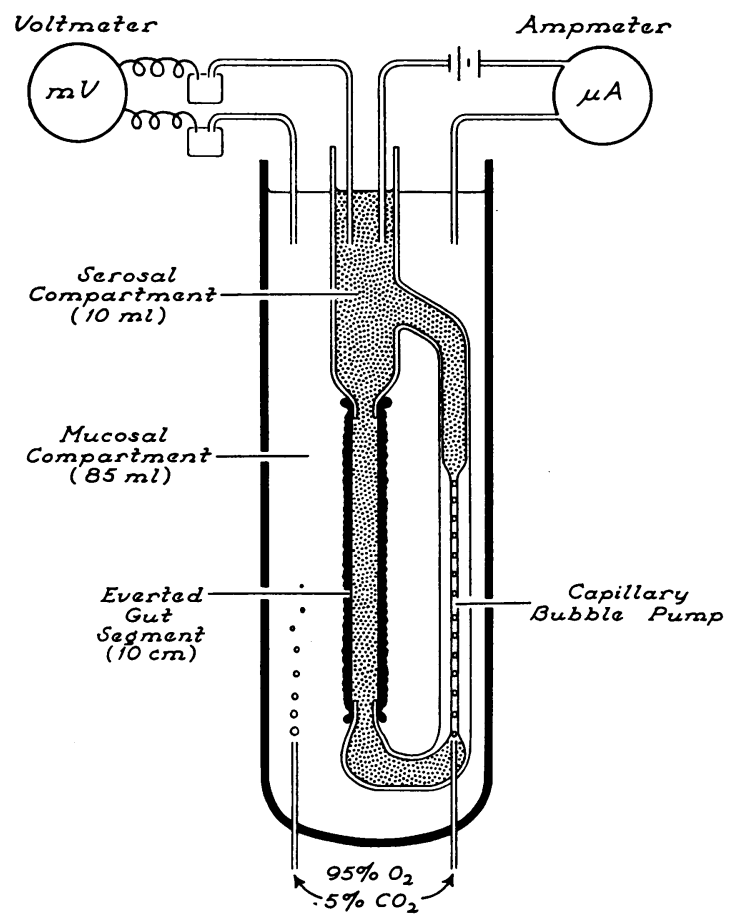

Fig. 1. Diagrammatic Representation of the in VITRO PERFUSION APPARATUS. During actual measurements of potential differences across the intestinal wall, the two salt bridges were extended down into the mucosal and serosal compartments to the level of the midgut segment. Similarly, during short-circuiting procedures, electrodes were arranged symmetrically about the intestinal segment.

carrier. This carrier contained the serosal perfusion solution (10 $\mathrm{ml}$ volume), which was constantly circulated through the gut segment by means of a capillary bubble pump. The outer vessel contained the mucosal perfusion solution ( $85 \mathrm{ml}$ volume), which was constantly mixed by bubbling $95 \%$ oxygen : $5 \%$ carbon dioxide through it. This entire apparatus was placed in a constantly stirred water bath (not shown in Figure 1) at $37^{\circ} \mathrm{C}$.

Labeled and unlabeled bile salts were added, as indicated in the Results section, and a rate constant for the movement of bile salt across the intestinal wall, expressed as micromicromoles of bile salt moving per minute per centimeter length of intestine, was determined. Net water movement was estimated from the rate of dilution of a tracer amount of tritiated inulin added to the serosal compartment and is expressed as microliters per minute per centimeter.

Potential differences across the intestine were measured as described earlier (10). During actual measurements, the two bridges were inserted into the serosal and mucosal compartments to the midlevel of the intestinal segment. Maximal voltage readings were obtained when the two junctions of the intestinal segment to the glass 
carrier were insulated by wrapping with rubber sheeting coated with silicone grease. ${ }^{4}$ The intestinal segment was short-circuited by application of an external current through platinum electrodes in the mucosal and serosal fluids.

It should be emphasized that with this perfusion system bile salt transport continued linearly for at least 4 hours, and it was possible to measure unidirectional bile salt and net water flux rates under experimental conditions in which concentration and osmotic gradients as well as potential differences across the membrane and the $\mathrm{pH}$ of the perfusing solutions remained essentially fixed throughout the experimental period.

3) In vivo intestinal segments. The flux of ${ }^{14} \mathrm{C}$-labeled bile salts from the intestine into the vascular space could be monitored by following the appearance of radioactivity in the bile, since under the conditions of these experiments liver clearance of bile salts was not rate limiting. The small intestine was ligated at the ligament of Treitz and transected at the ileocecal junction; care was taken during these manipulations to avoid damage to the intestinal blood supply. The entire small intestine was then flushed with isotonic saline. A $10-\mathrm{cm}$ intestinal segment was isolated, washed four more times with saline, and filled with $1.3 \mathrm{ml}$ of the test solution containing ${ }^{14} \mathrm{C}$ labeled bile salt. After 2 minutes, $0.3 \mathrm{ml}$ of the solution was removed for determination of bile salt specific activity. Bile drainage from a common duct catheter was collected at 3-minute intervals directly into counting vials. After a 45-minute collection period the residual test solution was aspirated for repeat determination of bile acid specific activity; in addition, the length of the test segment and its position along the small bowel were ascertained. The absorption rate (in micromicromoles per minute per centimeter) of bile salt was then calculated from the appearance rate of ${ }^{14} \mathrm{C}$ in the bile and the mean specific activity of bile salt in the lumen of the intestinal segment.

$\mathrm{pH}$ of the luminal test solution as a function of time was directly measured with $\mathrm{pH}$ and reference electrodes inserted into the cut ends of the intestine and tied in place.

\section{Radioactivity determinations}

All buffer solutions and bile samples were assayed for ${ }^{14} \mathrm{C}$ or ${ }^{3} \mathrm{H}$ content with the scintillation fluid described by Bray (11) in a Packard liquid scintillation counter, model 314E; quenching was corrected for by internal standardization (12).

\section{Results}

The taurine conjugate of cholic acid is the predominant naturally occurring bile acid in the rat. For this reason taurocholate and cholate, ${ }^{5}$

\footnotetext{
4 Dow Corning Corp., Midland, Mich.

5 Throughout this paper the terms "taurocholate" and "cholate" are used in the generic sense when no distinction between the ionized and un-ionized forms of these bile acids
}

respectively, were used as the test substances in these studies to evaluate transport mechanisms that result in net movement of conjugated and unconjugated bile salts across the intestinal wall. Since the various transport phenomena must relate to bile salt activity, the concentrations of both bile salts were kept well below their respective critical micellar concentrations; at these low concentrations the activity coefficients for both substances $\left(\gamma_{\mathrm{BA}}\right)$ were considered to approach 1.0 so that bile salt concentration approximated bile salt activity. Initial studies were performed under in vitro conditions in which activity, $\mathrm{pH}$, osmotic, and electrical variables could be rigidly controlled; these experiments were then extended to the intact animal as far as was feasible.

\section{In vitro studies}

1) Net water movement and bile salt reflection coefficients. Since water absorption may effect the movement of a given substance through the process of solvent drag, it was first necessary to establish the effect of bulk water flow upon unidirectional bile salt fluxes with the apparatus illustrated in Figure 1.

Initial data were obtained to determine the magnitude of net water movement under the conditions of these experiments. In five studies using jejunal segments, net mucosal-to-serosal water movement (net $\overrightarrow{\mathrm{H}}_{2} \overrightarrow{\mathrm{O}}_{\mathrm{m}-\mathrm{s}}$ ) amounted to $1.05 \pm 0.11 \mu \mathrm{l}$ per minute per $\mathrm{cm}( \pm 1 \mathrm{SD})$ in the absence of glucose in the perfusing Krebs buffer; when glucose was added to both the mucosal and serosal solutions to yield a final concentration of $200 \mathrm{mg}$ per $100 \mathrm{ml}$, net $\overrightarrow{\mathrm{H}}_{2} \overrightarrow{\mathrm{O}}_{\mathrm{m}-\mathrm{s}}$ in these same segments doubled to $2.27 \pm 0.76$ $\mu \mathrm{l}$ per minute per $\mathrm{cm}$. Similarly, in three ileal segments net $\overrightarrow{\mathrm{H}}_{2} \mathrm{O}_{\mathrm{m}-\mathrm{s}}$ equaled $1.58 \pm 0.09$ and $2.52 \pm 0.45 \mu \mathrm{l}$ per minute per $\mathrm{cm}$ in the absence and presence of glucose, respectively.

The effects of net $\overrightarrow{\mathrm{H}}_{2} \mathrm{O}_{m-s}$ upon the mucosalto-serosal flux of bile salt $\left(\overrightarrow{\mathrm{BA}}_{\mathrm{m}-\mathrm{s}}\right)$ were next determined in order to calculate the reflection coefficients for both taurocholate and cholate.

is intended. In specific situations in which this differentiation is made, ionized bile salts are referred to as "taurocholate ions" and "cholate ions"; the un-ionized acid forms are referred to as "un-ionized taurocholic acid" and "un-ionized cholic acid." 
TABLE I

Reflection coefficients for taurocholate and cholate in the intestine*

\begin{tabular}{|c|c|c|c|c|c|c|c|}
\hline \multicolumn{2}{|c|}{ Experiment } & \multirow[t]{2}{*}{ Bile salt } & \multirow[t]{2}{*}{$\begin{array}{l}\text { Segment } \\
\text { no. }\end{array}$} & \multirow[t]{2}{*}{$\begin{array}{l}\text { Procedure producing change } \\
\text { in net } \overrightarrow{\mathrm{H}_{2} \mathrm{O}_{m \rightarrow-s}}\end{array}$} & \multirow{2}{*}{ 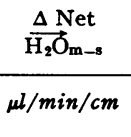 } & \multirow{2}{*}{ 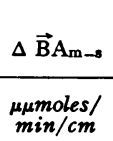 } & \multirow[t]{2}{*}{$\sigma_{\mathrm{BA}}$} \\
\hline & & & & & & & \\
\hline \multirow[t]{3}{*}{ A } & 1 & $\mathrm{CA}$ & 2 & $+\underset{\text { fluid }}{100 \mathrm{mOsm}}$ to serosal & 2.42 & 65 & 0.95 \\
\hline & 2 & TCA & 9 & $\begin{array}{l}+100 \mathrm{mOsm} \text { to serosal } \\
\text { fluid }\end{array}$ & 2.89 & 57 & 0.96 \\
\hline & 3 & TCA & 9 & $+\underset{\text { fluid }}{300 \text { mOsm to serosal }}$ & 6.62 & 47 & 0.99 \\
\hline \multirow[t]{4}{*}{ B } & 1 & CA & 2 & $\begin{array}{l}200 \mathrm{mg} \text { per } 100 \mathrm{ml} \\
\text { glucose to both com- } \\
\text { partments }\end{array}$ & 1.01 & 15 & 0.97 \\
\hline & 2 & CA & 2 & $\begin{array}{l}200 \mathrm{mg} \text { per } 100 \mathrm{ml} \\
\text { glucose to both com- } \\
\text { partments }\end{array}$ & 1.85 & 46 & 0.95 \\
\hline & 3 & TCA & 2 & $\begin{array}{l}200 \mathrm{mg} \text { per } 100 \mathrm{ml} \\
\text { glucose to both com- } \\
\text { partments }\end{array}$ & 1.62 & 64 & 0.92 \\
\hline & 4 & TCA & 2 & $\begin{array}{l}200 \mathrm{mg} \text { per } 100 \mathrm{ml} \\
\text { glucose to both com- } \\
\text { partments }\end{array}$ & 0.91 & 9 & 0.98 \\
\hline
\end{tabular}

* $\mathrm{TCA}=$ taurocholate $; \mathrm{CA}=$ cholate $; \overrightarrow{\mathrm{H}}_{2} \mathrm{O}_{\mathrm{m} \rightarrow \mathrm{s}}=$ mucosal-to-serosal water movement $; \overrightarrow{\mathrm{B}} \mathrm{A}_{\mathrm{m} \rightarrow \mathrm{s}}=$ mucosal-to-serosal flux of bile salt; $\sigma_{\mathrm{BA}}=$ bile salt reflection coefficient.

In these studies both the mucosal and serosal fluids had bile salt concentrations of $500 \mathrm{~m} \mu$ moles per $\mathrm{ml}$. After an initial 45-minute equilibration period simultaneous determinations of net $\overrightarrow{\mathrm{H}_{2}} \mathrm{O}_{\mathrm{m}-\mathrm{s}}$ and $\overrightarrow{\mathrm{B}} \mathrm{A}_{\mathrm{m}-\mathrm{s}}$ were made over a 30 -minute period; then the rate of net water movement was altered by adding either mannitol to the serosal compartment or glucose $(200 \mathrm{mg}$ per 100 $\mathrm{ml})$ to both the mucosal and serosal solutions; repeat determinations of net $\overrightarrow{\mathrm{H}}_{2} \mathrm{O}_{\mathrm{m}-\mathrm{s}}$ and $\overrightarrow{\mathrm{B}} \mathrm{A}_{\mathrm{m}-\mathrm{s}}$ were then performed. The changes in net mucosal-to-serosal water movement $(\Delta$ net $\overrightarrow{\mathrm{H}_{2} \mathrm{O}_{m-8}}$ ) and in mucosal-to-serosal bile salt fluxes $\left(\Delta \overrightarrow{\mathrm{B}} \mathrm{A}_{\mathrm{m}-\mathrm{s}}\right)$ brought about by these experimental procedures are shown in Table $\mathrm{I}$; these data enable one to then calculate the bile salt reflection coefficient $\left(\sigma_{\mathrm{BA}}\right)$ by means of the formula (13) :

$$
\sigma_{\mathrm{BA}}=1-\frac{\Delta \overrightarrow{\mathrm{B}} \mathrm{A}_{\mathrm{m}-\mathrm{s}}}{\left(\Delta \text { net } \overrightarrow{\left.\mathrm{H}_{2} \mathrm{O}_{\mathrm{m}-\mathrm{s}}\right)\left([\overrightarrow{\mathrm{BA}}]_{\mathrm{m}}\right)}\right.},
$$

where $[\mathrm{BA}]_{\mathrm{m}}$ equals the mucosal solution bile salt concentration. As can be seen, the values of $\sigma_{\mathrm{BA}}$ are essentially the same whether the change in water movement was induced by an osmotic gradient or by the addition of glucose to the perfusing solutions; in addition, there appears to be no significant difference between the values of $\sigma_{\mathrm{BA}}$ for taurocholate and cholate. Thus, the mean value of 0.96 is used in order to calculate solvent drag effects. Furthermore, since, as will be shown, the active transport of bile salt is not glucose dependent and since it was desirable to minimize net $\overrightarrow{\mathrm{H}_{2}} \mathrm{O}_{m-8}$, glucose was not added to the Krebs buffer solution in any of the subsequent experiments.

2) Localization of active transport sites. Having defined the effects of bulk water flow, we could then undertake experiments designed to identify and localize active processes operative in the transport of bile salts. This was accomplished by measuring bidirectional flux rates for bile salts across the intestinal mucosa when the transmural electrochemical gradient was fixed essentially at zero (14). In these experiments the serosal and mucosal fluids contained identical bile salt concentrations, $500 \mathrm{~m} \mu$ moles per $\mathrm{ml}$, and the potential difference across the intestinal wall was always $<2.0 \mathrm{mv}$. In Figure 2 the mucosal-to-serosal fluxes $\left(\overrightarrow{\mathrm{B}} \mathrm{A}_{\mathrm{m}-\mathrm{s}}\right)$ at different levels of the small intestine for taurocholate and cholate are shown in the upper panels, and the serosal-to-mucosal fluxes $\left(\overrightarrow{\mathrm{BA}}_{\mathrm{s}-\mathrm{m}}\right)$ are illustrated in the lower panels. 


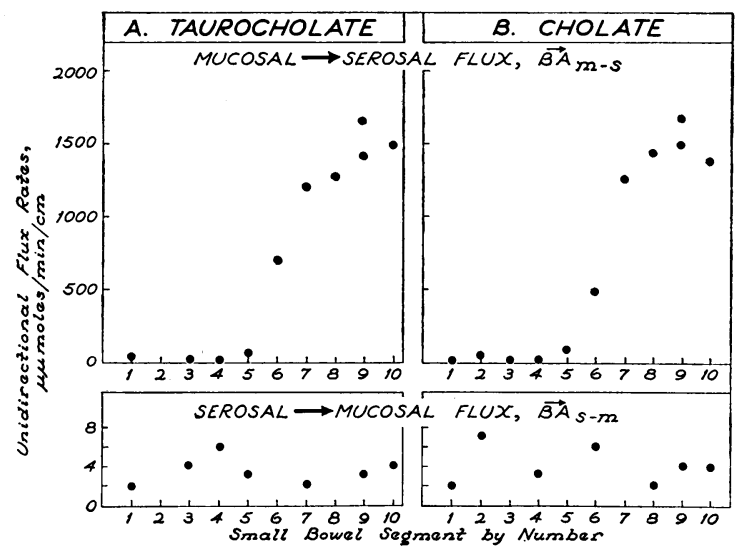

Fig. 2. Bidirectional fluX Rates for taurocholate AND CHOLATE. Both the mucosal-to-serosal flux (upper panels) and the serosal-to-mucosal flux (lower panels) of taurocholate and cholate were determined under conditions of an electrochemical potential gradient equal to zero across the intestinal segments. The plotted data represent the observed flux rates uncorrected for solvent drag effects.

The values of $\overrightarrow{\mathrm{B}} \mathrm{A}_{\mathrm{B}-\mathrm{m}}$ for both taurocholate and cholate were very low under these experimental conditions at every level of the intestine and averaged $3.0 \pm 1.6$ and $4.0 \pm 1.9 \mu \mu$ moles per minute per $\mathrm{cm}$, respectively. In contrast, $\overrightarrow{\mathrm{B}} \mathrm{A}_{\mathrm{m}-\mathrm{s}}$ in the proximal five segments averaged $23 \pm 10$ $\mu \mu$ moles per minute per $\mathrm{cm}$ for taurocholate and $33 \pm 21 \mu \mu$ moles per minute per $\mathrm{cm}$ for cholate. These data, therefore, gave values for the flux ratio $\left(\overrightarrow{\mathrm{B}} \mathrm{A}_{\mathrm{m}-\mathrm{s}} / \overrightarrow{\mathrm{B}} \mathrm{A}_{\mathrm{s}-\mathrm{m}}\right)$ significantly $>1.0$ in the proximal half of the intestine and so implied the presence of active transport. However, a portion of the $\overrightarrow{\mathrm{B}} \mathrm{A}_{\mathrm{m}-\mathrm{s}}$ was due to the solvent drag effect of net mucosal-to-serosal water movement; the magnitude of this component of the flux could be calculated as the product of net $\overrightarrow{\mathrm{H}}_{2} \mathrm{O}_{m-8}$ times the mucosal bile salt concentration times the quantity, $\left(1-\sigma_{\mathrm{BA}}\right)$. Since net $\overrightarrow{\mathrm{H}}_{2} \mathrm{O}_{m-\mathbf{s}}$ in these segments equaled $1.05 \pm 0.11 \mu \mathrm{l}$ per minute per $\mathrm{cm}$, the calculated bile salt flux due to solvent drag was approximately $21 \mu \mu$ moles per minute per $\mathrm{cm}$. When this calculated flux rate was subtracted from the observed mean values of $\overrightarrow{\mathrm{B}} \mathrm{A}_{\mathrm{m}-\mathrm{s}}$, the resulting differences equaled $2 \pm 10$ $\mu \mu$ moles per minute per $\mathrm{cm}$ for taurocholate and $12 \pm 21 \mu \mu$ moles per minute per $\mathrm{cm}$ for cholate. Since these corrected values for $\overrightarrow{\mathrm{B}} \mathrm{A}_{\mathrm{m}-\mathrm{s}}$ did not significantly differ from the observed values for $\overrightarrow{\mathrm{B}} \mathrm{A}_{\mathrm{s}-\mathrm{m}}$, the flux ratios equaled 1.0 ; clearly then, there was no active transport of either taurocholate or cholate in the proximal five small intestinal segments.

In contrast, even when solvent drag effects were taken into consideration, significant deviations of the flux ratios to values far greater than 1.0 were found in all levels of the distal small intestine, with maximal values manifest in the terminal three segments. There was no apparent difference between the flux ratio values from cholate or taurocholate at any level. Finally, in similar experiments performed in ileal segments exposed to iodoacetamide, $1 \times 10^{-4} \mathrm{M}$, the flux ratio values dropped to 1.0 . These data therefore unequivocally established the presence of active transport mechanisms for both the conjugated and unconjugated bile salts in the distal half of the small bowel.

3) Quantification of the active and passive transport of taurocholate and cholate ions. The next series of experiments was designed to quantitate and compare the magnitude of the active transport fluxes for both taurocholate and cholate and, in addition, to investigate the passive flux of both of these ions down activity gradients. In these studies $\overrightarrow{\mathrm{B}} \mathrm{A}_{\mathrm{m}-\mathrm{s}}$ was measured at varying concentrations of bile salt in the mucosal solution using intestinal segments 2 and 9 ; since the serosal fluid contained no bile salt, increases in concentration in the mucosal solution resulted in corresponding increases in the transmural bile salt activity gradient. The results of these experiments are shown in Figure 3.

Although the proximal small bowel (segment 2) lacks active transport mechanisms, bile salt, nevertheless, does move passively across the intestinal wall when an activity gradient exists between the mucosal and serosal solution; thus, as is shown in Figure 3, $\overrightarrow{\mathrm{B}} \mathrm{A}_{\mathrm{m}-\mathrm{s}}$ measured in the second intestinal segment increased in a linear manner with increases in the mucosal solution concentration of either taurocholate or cholate. The value of $\overrightarrow{\mathrm{B}} \mathrm{A}_{\mathrm{m}-\mathrm{s}}$ at any given concentration of bile salt in the mucosal compartment is the sum of two passive fluxes: 1) bile salt movement due to solvent drag and 2) bile salt diffusion down the existing activity gradient. The magnitude of the solvent drag effect at any mucosal solution concentration could be calcu- 
TABLE II

Magnitude of each of the three processes involved in the in vitro transport of taurocholate and cholate in the proximal jejunum (segment 2) and distal ileum (segment 9)

\begin{tabular}{|c|c|c|c|c|c|}
\hline & & \multicolumn{2}{|c|}{ Taurocholate } & \multicolumn{2}{|c|}{ Cholate } \\
\hline & & Segment 2 & Segment 9 & Segment 2 & Segment 9 \\
\hline (A) & $\begin{array}{l}\text { Active transport maximum, } \\
\mu \mu \mathrm{moles} / \mathrm{min} / \mathrm{cm}\end{array}$ & 0 & $1,380 \pm 350$ & 0 & $1,490 \pm 110$ \\
\hline (B) & $\begin{array}{l}\text { Passive ionic diffusion, } \\
\mu \mu m o l e s / \mathrm{min} / \mathrm{cm} / \\
1.0 \mathrm{mM} \text { gradient }\end{array}$ & $89 \pm 12$ & $89 \pm 12^{*}$ & $83 \pm 7$ & $83 \pm \quad 7^{*}$ \\
\hline (C) & 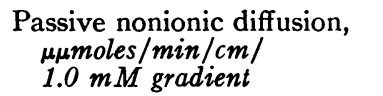 & 0 & 0 & $610 \pm 95$ & $610 \pm 95^{*}$ \\
\hline
\end{tabular}

* Assumed to equal that value determined experimentally in segment 2 .

lated; these values are indicated by the dashed lines in Figure 3. After subtracting the values of the bile salt flux due to water transport from the observed values of $\overrightarrow{\mathrm{B}} \mathrm{A}_{\mathrm{m}-\mathrm{s}}$, one can obtain diffusion constants that quantitated the magnitude of the passive fluxes across the bowel wall of taurocholate and cholate ions expected for a given activity gradient. These constants are shown in line B of Table II and equal $89 \pm 12$ and $83 \pm 7 \mu \mu$ moles per minute per $\mathrm{cm}$ per $1.0 \mathrm{mM}$ gradient for taurocholate and cholate, respectively.

When similar experiments were performed using intestinal segment 9, as shown in Figure 3, the relationship of $\overrightarrow{\mathrm{B}} \mathrm{A}_{\mathrm{m}-\mathrm{s}}$ to the concentration of bile salt in the mucosal solution clearly manifested the kinetics characteristic of a saturable carrier system, as would be expected in an intestinal area already shown to transport bile salt actively. However, at each mucosal solution concentration the value of $\vec{B} A_{m-8}$ equals the summation of three separate fluxes resulting from 1) the active transport of bile salt, 2) the passive ionic diffusion of bile salt down the existing activity gradient, and 3) bile salt movement due to solvent drag. The magnitude of the solvent drag effect could again be calculated, since one knew that $\overrightarrow{\mathrm{H}_{2}} \mathrm{O}_{\mathrm{m}-\mathrm{s}}$ in these segments equaled $1.58 \pm 0.09 \mu \mathrm{l}$ per minute per $\mathrm{cm}$; similarly, if one assumed that the passive permeability characteristics with respect to ionic diffusion of taurocholate and cholate in the ileal segments were similar to those just determined for the jejunum, then he could estimate the magnitude of the bile salt flux due to passive diffusion of these ions down the activity gradient. Thus, by subtracting the sum of these two passive fluxes from the observed values of $\overrightarrow{\mathrm{B}} \mathrm{A}_{\mathrm{m}-\mathrm{s}}$, one obtains the data plotted as the dotted lines in Figure 3, which describe the magnitude of the calculated active transport flux as a function of the concentration of bile salt in the mucosal solution.

To verify that the passive permeability characteristics of segment 9 were indeed similar to

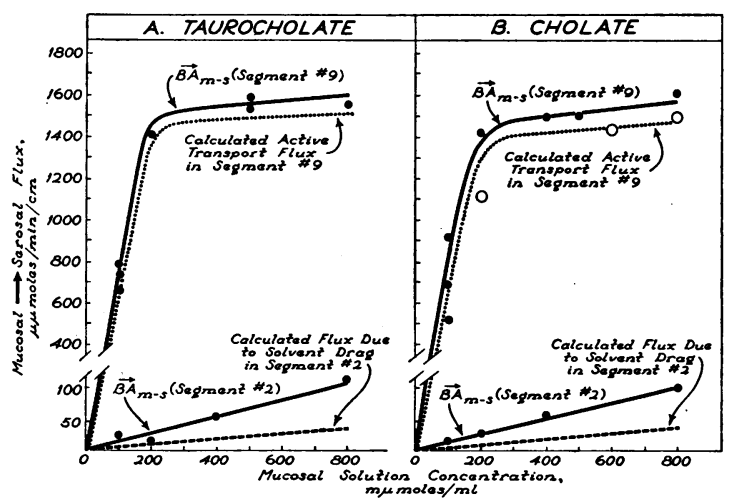

Fig. 3. ACtive tRANSPORT AND PASSIVE IONIC DIFFUSION OF BILE SALT. Intestinal segment 2 was taken as an area of intestine that lacked active transport. The mucosal-to-serosal flux of both taurocholate and cholate was determined in this segment as a function of the transmural concentration gradient. After correction of these observed fluxes for the flux expected from solvent drag, it was possible to calculate the ionic diffusion constants for these two bile salts. Segment 9 was taken as an area that possessed active bile salt transport. When the observed fluxes, plotted as a function of the mucosal solution concentration, were corrected for net bile salt movement due to passive phenomena, values for the active transport flux of taurocholate and cholate were obtained. 


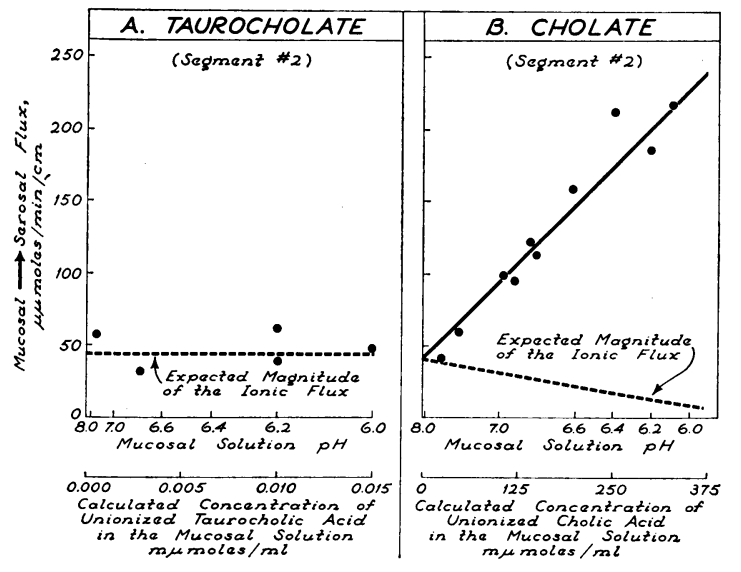

Fig. 4. NonIonic DIfFUsion of UN-IONIZED CHOLIC ACID. In these studies the mucosal solution contained a concentration of $500 \mathrm{~m} \mu$ moles per $\mathrm{ml}$ of either taurocholate or cholate, whereas the serosal solution contained no bile salt. The mucosal-to-serosal flux rate was then determined under experimental conditions in which the mucosal solution buffer was adjusted to $\mathrm{pH}$ values that varied from 6.0 to 8.0. These flux rates are plotted as a function of the calculated concentration of un-ionized bile salt present in the mucosal solution under each of these $\mathrm{pH}$ conditions.

those of segment 2, we performed three experiments using equal concentrations of cholate in both the mucosal and serosal solutions. If this assumption were valid, then in these studies in which the bile salt activity gradient was eliminated, the observed values of $\overrightarrow{\mathrm{B}} \mathrm{A}_{\mathrm{m}-\mathrm{s}}$, after correction for solvent drag effects, should give a direct measure of the active bile salt flux. As shown by the open circles in Figure $3 \mathrm{~B}$, this was the case; the values determined in this experiment fell very close to the line representing the calculated active transport flux. Hence, in line B of Table II the constants for the passive diffusion of taurocholate and cholate ions in segment 9 are assumed to approximately equal those experimentally determined in segment 2 .

These studies indicated that the transport maxima $\left(\mathrm{V}_{\max }\right)$ for conjugated and unconjugated bile salts were similar. In eight additional studies using concentrations of $800 \mathrm{~m} \mu$ moles per $\mathrm{ml}$ of either taurocholate or cholate in both the mucosal and serosal solutions, the mean value found in the ninth intestinal segment for the active flux of taurocholate was $1,380 \pm 350$ $\mu \mu$ moles per minute per $\mathrm{cm}$ and for cholate equaled 1,490 $\pm 110 \mu \mu$ moles per minute per $\mathrm{cm}$ (line A of Table II). The addition of glucose to the perfusing media $(200 \mathrm{mg}$ per $100 \mathrm{ml}$ ) did not alter the observed rates. Clearly these ileal segments actively transported both the conjugated and unconjugated bile salt with equal maximal velocities.

This finding suggested that the active transport site might not differentiate between the two kinds of bile salt; to evaluate this possibility further, we studied more carefully the first order kinetics of the transport processes by means of Lineweaver-Burke plots of the transport velocities of taurocholate and cholate at varying concentrations of these substances in the perfusing solutions. By this means it was determined that the values of $K_{m}$ were the same ( $88 \mathrm{~m} \mu$ moles per $\mathrm{ml}$ ) for the transport of both the conjugated and unconjugated bile salts. These results, along with those of the preceding experiments, strongly imply that the active transport carrier mechanism does not distinguish between the conjugated and unconjugated forms of the bile salt.

4) Nonionic diffusion of bile acids. The experimental data concerning the active and passive movement of taurocholate and cholate that have so far been described were obtained under $\mathrm{pH}$ conditions (7.4) at which essentially all of the bile salt would be present in solution as negatively charged ions. Since the un-ionized acid form of the bile salts would theoretically diffuse across the intestinal membrane in response to a given activity gradient more readily than the ionized form, experiments were undertaken to determine the rate constants for this process of nonionic diffusion using intestinal segment 2. In these studies, illustrated in Figure 4 , the mucosal solution had a constant concentration of $500 \mathrm{~m} \mu$ moles per $\mathrm{ml}$ of either the conjugated or unconjugated bile salt, whereas no bile salt was present in the serosal compartment. The $\mathrm{pH}$ of the mucosal Krebs solution in different experiments was maintained at values ranging from 6.0 to 8.0 by the addition of either concentrated hydrochloric acid or $90 \%$ sodium hydroxide. The serosal Krebs solution was at a constant $\mathrm{pH}$ of 7.4. $\quad \overrightarrow{\mathrm{B}} \mathrm{A}_{\mathrm{m}-\mathrm{s}}$ was measured and corrected for solvent drag effects in order to determine the magnitude of the passive flux of bile salt down the existing mucosal-toserosal activity gradient. These values are 
plotted in Figure 4 against the theoretical concentration of un-ionized bile acid in the mucosal solution as calculated from the HendersonHasselbalch equation.

Since the pK of taurocholate is $1.5,>99.9 \%$ of this bile salt was present in ionic form throughout the range of mucosal solution $\mathrm{pH}$ values tested; hence, there could be no nonionic diffusion of this conjugated bile salt under these experimental conditions. A rate constant of 0 is therefore given for this process in line $\mathrm{C}$ of Table II. Any flux of taurocholate in this study must represent passive ionic diffusion; since the activity gradient equaled $500 \mu$ moles per $\mathrm{L}$, the expected magnitude of this flux, shown as a dashed line in Figure 4A, should equal approximately $45 \mu \mu$ moles per minute per $\mathrm{cm}$. The five experimentally determined points fall very close to this predicted value and, as expected, the flux rates do not vary with changes in $\mathrm{pH}$ of the mucosal solution.

In contrast, the $\mathrm{pK}$ of cholate is 6.4 , so that relatively slight changes in the $\mathrm{pH}$ of the mucosal solution in the range of 6.0 to 8.0 result in marked changes in the relative amounts of cholate ion and un-ionized cholic acid in the solution. The effects of these $\mathrm{pH}$ changes on the passive flux of cholate across the intestine are shown in Figure 4B. At a $\mathrm{pH}$ of 8.0 where $98 \%$ of the bile salt is present as cholate ions, the mucosal-to-serosal flux was approximately $41 \mu \mu$ moles per minute per $\mathrm{cm}$, a value that is predictable on the basis of the existing ionic activity gradient (line $\mathrm{B}$, Table II). At lower $\mathrm{pH}$ values, the flux rate increased in a linear relationship to the calculated concentration of un-ionized cholic acid in the mucosal solution. Under these conditions the observed movement of cholic acid across the intestine represented the sum of the passive fluxes of two chemical entities - the diffusion of cholate ions and the diffusion of un-ionized cholic acid down their respective activity gradients. The theoretical gradient for cholate ions decreased from approximately $490 \mathrm{~m} \mu$ moles per $\mathrm{ml}$ at a $\mathrm{pH}$ of 8.0 to only $125 \mathrm{~m} \mu$ moles per $\mathrm{ml}$ at a $\mathrm{pH}$ of 5.9 ; hence, the expected magnitude of the passive ionic flux of cholate ions, indicated by the dashed line in Figure 4B, calculated on the basis of these gradients decreased from 41 $\mu \mu$ moles per minute per $\mathrm{cm}$ at a $\mathrm{pH}$ of 8.0 to only $10 \mu \mu$ moles per minute per $\mathrm{cm}$ at a $\mathrm{pH}$ of 5.9. By subtracting the values for ionic flux from the observed values of $\vec{B} A_{m-s}$, one could then calculate a diffusion constant for un-ionized cholic acid. As indicated in line C of Table II this constant equals $610 \pm 95 \mu \mu$ moles per minute per $\mathrm{cm}$ per $1.0 \mathrm{mM}$ gradient of un-ionized cholic acid across the wall of the intestinal segment. Although not tested experimentally, this constant was assumed to be the same in ileal segments (segment 9).

5) Exchange diffusion. Although gross exchange diffusion could be excluded on the basis of the results of some of the previous experiments, the three studies shown in Table III were undertaken to evaluate this process more definitely. With intestinal segment 9, the serosal-to-mucosal flux of ${ }^{14} \mathrm{C}$-labeled bile salt was measured both in the presence and in the absence of bile salt in the mucosal solution. In experiments $\mathrm{A} 1, \mathrm{~B} 1$, and $\mathrm{C} 1$, in which no bile salt was present in the mucosal solution, the values of $\overrightarrow{\mathrm{B}} \mathrm{A}_{\mathrm{s}-\mathrm{m}}$ varied from 37 to $51 \mu \mu$ moles per minute per $\mathrm{cm}$; these flux rates were compatible with the bile salt activity gradient that existed between the serosal and mucosal solutions. In experiments A2, B2, and $\mathrm{C} 2$ active bile salt transport was induced by the addition of either cholate or taurocholate to the mucosal solution. Under these experimental conditions $\overrightarrow{\mathrm{B}} \mathrm{A}_{\mathrm{s}-\mathrm{m}}$ clearly did not increase; thus, these results eliminate exchange diffusion as a significant transport process for bile acid across the intestinal wall.

6) Comparison of in vitro data obtained in everted gut sacs and in the perfusion apparatus. As shown by previous investigators $(2,3,5)$, experiments in this laboratory using everted gut

TABLE III

Evidence for the absence of exchange diffusion for cholate and taurocholate in the terminal ileum (segment 9)

\begin{tabular}{|c|c|c|c|c|c|}
\hline \multirow{2}{*}{\multicolumn{2}{|c|}{$\begin{array}{l}\text { Experi- } \\
\text { ment }\end{array}$}} & \multirow[b]{2}{*}{ Bile salt } & \multicolumn{2}{|c|}{$\begin{array}{c}\text { Bile salt } \\
\text { concentration }\end{array}$} & \multirow{2}{*}{$\begin{array}{c}\underset{\text { Serosal }}{\text { mucosal }} \\
\text { flux } \\
\overrightarrow{\mathbf{B}} \mathbf{A}_{\mathbf{s}-\mathbf{m}}\end{array}$} \\
\hline & & & Mucosa & Serosa & \\
\hline & & & \multicolumn{2}{|c|}{$m \mu m o l e s / m l$} & $\underset{\min / \mathrm{cm}}{\mu \mu m o l e s /}$ \\
\hline $\mathbf{A}$ & $\begin{array}{l}1 \\
2\end{array}$ & Cholate & $\begin{array}{r}0 \\
400\end{array}$ & $\begin{array}{l}400 \\
400\end{array}$ & $\begin{array}{l}45 \\
10\end{array}$ \\
\hline B & $\begin{array}{l}1 \\
2\end{array}$ & Cholate & $\begin{array}{r}0 \\
400\end{array}$ & $\begin{array}{l}400 \\
400\end{array}$ & $\begin{array}{r}37 \\
0\end{array}$ \\
\hline $\mathrm{C}$ & $\begin{array}{l}1 \\
2\end{array}$ & Taurocholate & $\begin{array}{r}0 \\
400\end{array}$ & $\begin{array}{l}400 \\
400\end{array}$ & $\begin{array}{r}51 \\
4\end{array}$ \\
\hline
\end{tabular}




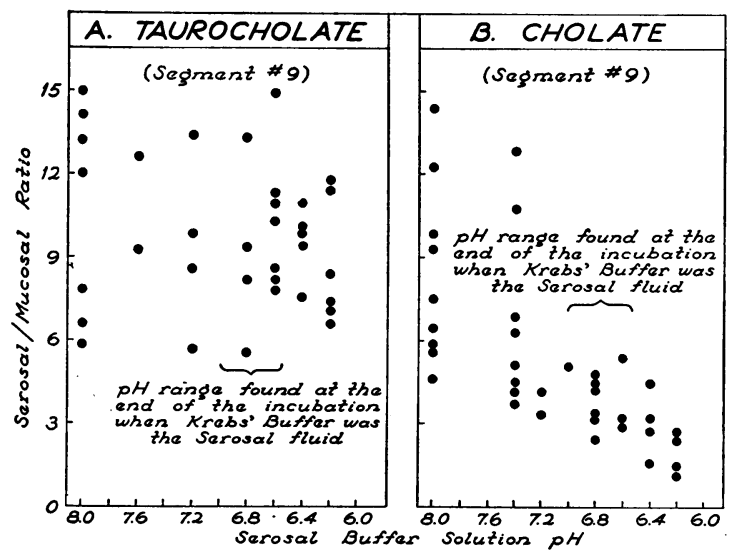

Fig. 5. Bile salt transport in the everted gut SaC AT DIFFERENT SEROSAL FLUID PH VALUES. In these studies, only intestinal segment 9 was used; the mucosal fluid consisted of Krebs bicarbonate buffer, and the serosal compartment was filled with an isosmotic solution of either Tris or phosphate buffer that was adjusted to $\mathrm{pH}$ values varying from 6.2 to 8.0 . The serosal/mucosal ratio of taurocholate and cholate that had developed by the end of a 90 -minute incubation period is plotted as a function of the serosal solution $\mathrm{pH}$. Also indicated in this diagram is the $\mathrm{pH}$ range found in the serosal compartment when simple Krebs bicarbonate buffer was used as the serosal fluid.

sacs demonstrated essentially no net movement of taurocholate or cholate in proximal intestinal segments. In ileal segments net mucosal-toserosal movement of both conjugated and unconjugated bile acids occurred; the observed serosal/mucosal ratios were, however, approximately three times as high for taurocholate as for cholate. Thus, there are discrepancies between the results obtained in everted gut sacs and those obtained in the in vitro perfusion apparatus; however, the clear separation and quantification of three distinctly different transport phenomena in the latter experiments provide the explanation for these apparent differences.

In everted gut sacs prepared from the terminal small bowel, active transport of both taurocholate and cholate results in the development of activity gradients which, in turn, cause passive serosal-to-mucosal diffusion of both of these bile salts. It is well known that a $\mathrm{pH}$ gradient develops between the mucosal (7.45 to 7.50) and serosal (6.50 to 7.00) solutions of these sacs (3). In the case of taurocholate only ionic diffusion would be expected, whereas with cholate the low $\mathrm{pH}$ of the serosal solution would allow both ionic and nonionic diffusion to take place. As a consequence of this augmented "backleak" of the unconjugated bile salt, lower serosal/mucosal ratios would be expected for cholate than for taurocholate. This dependency of the serosal/ mucosal ratios on the $\mathrm{pH}$ of the serosal compartment is illustrated by the data in Figure 5. In these experiments, everted gut sacs were made only from intestinal segment 9 ; the mucosal compartment contained Krebs solution at a $\mathrm{pH}$ of 7.4, whereas the serosal compartment contained a $100 \mathrm{mM}$ solution of either Tris or dibasic sodium phosphate buffer (made isosmotic with mannitol) adjusted to $\mathrm{pH}$ values of 6.2 to 8.0 in different experiments. The $\mathrm{pH}$ of these serosal buffers did not appreciably shift during the 90-minute incubation. As can be seen in Figure $5 \mathrm{~A}$, the range of values found for the serosal/mucosal ratios of taurocholate did not significantly vary with changes in the serosal compartment $\mathrm{pH}$. In contrast, however, the ratios developed with cholate were $\mathrm{pH}$ dependent; clearly, when the serosal solution was buffered at a $\mathrm{pH}$ of 7.4 or higher so that nearly all of the unconjugated bile salt in this compartment was present as cholate ions and nonionic diffusion was essentially eliminated, serosal/ mucosal ratios fully as high as those found with taurocholate developed. These data, therefore, establish that the apparent discrepancies in transport of conjugated and unconjugated bile salts manifest in everted gut sacs are an artifact of the $\mathrm{pH}$ gradient that develops in this preparation and do not reflect differences in relative transport rates.

\section{In vivo experiments}

Having defined the various transport phenomena operative in the intestine under in vitro conditions, we next undertook experiments to identify and quantitate each of these mechanisms for bile salt absorption in the intact animal.

1) Bile salt absorption in the proximal and distal small bowel. The four studies illustrated in Figure 6 show that striking differences exist in the in vivo absorption of conjugated and unconjugated bile salts from the proximal and distal small bowel. Absorption of taurocholate from the jejunal segment took place only slowly, whereas, in the ileal segment, absorption was 
essentially complete within 40 minutes. In contrast, absorption of cholate from segment 2 occurred almost as rapidly as from segment 9.

Since the $\mathrm{pH}$ of these unbuffered test solutions always dropped to $6.2 \pm 0.05$ within 3 to 5 minutes after being placed in the intestine, these data were consistent with the possibility that the three types of transport defined in vitro, i.e., active transport and passive ionic and nonionic diffusion, were also operative in vivo.

2) Quantification of active transport and passive ionic diffusion. In these studies ${ }^{14} \mathrm{C}$-labeled bile salts dissolved in isosmotic Tris buffer ( $\mathrm{pH} \mathrm{7.8)}$ were placed in either intestinal segment 2 or 9 ,

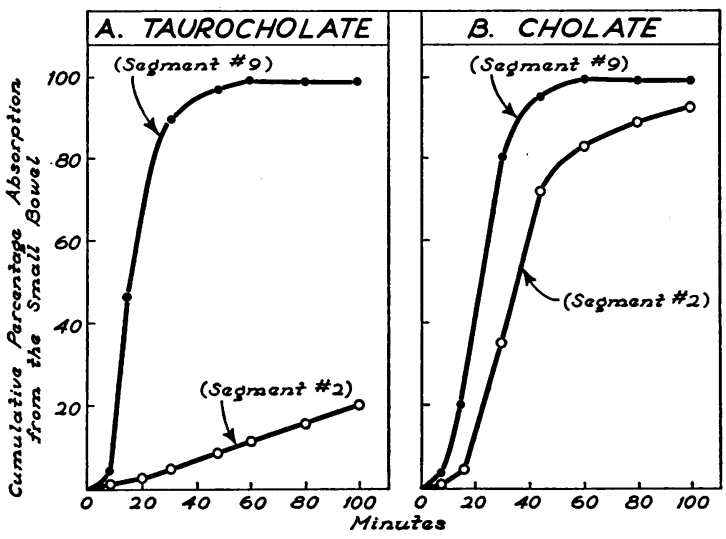

Fig. 6. The in vivo absorption of bile salt. The in vivo absorption of ${ }^{14} \mathrm{C}$-labeled taurocholate and cholate was studied by the instillation of isotopic labeled bile salts $(200 \mathrm{~m} \mu$ moles per $\mathrm{ml})$ into isolated proximal (segment 2) and into distal (segment 9) intestinal segments.

and the appearance of ${ }^{14} \mathrm{C}$ was followed in the biliary drainage. In preliminary experiments based on the recovery of radioactivity in the bile after portal vein administration of ${ }^{14} \mathrm{C}$-labeled bile salts, hepatic transport capacity was about five times greater than maximal intestinal absorption rates; hence, the rate of appearance of ${ }^{14} \mathrm{C}$-labeled bile salts in the bile reflects the rate of intestinal transport.

From these studies, shown in Figure 7, it can be calculated that the constant for passive ionic diffusion equals approximately $440 \pm 59$ and $400 \pm 80 \mu \mu$ moles per minute per $\mathrm{cm}$ for a $1 \mathrm{mM}$ gradient of taurocholate and cholate, respectively, in intestinal segment 2 . This constant

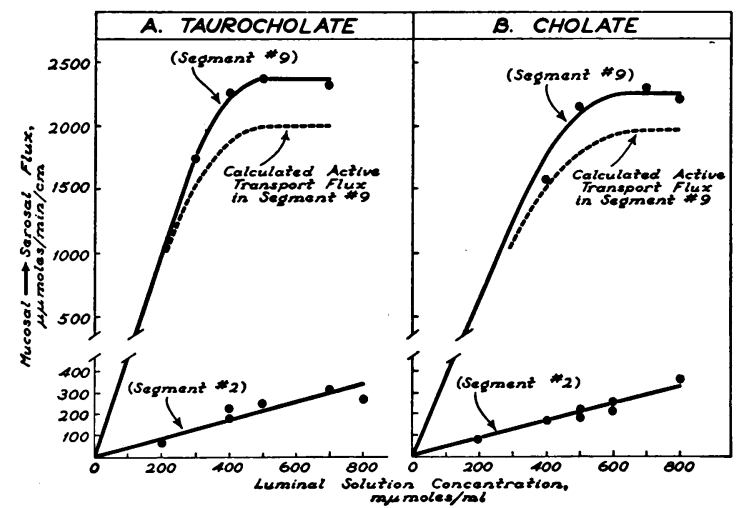

Fig. 7. ACtive tRANSPORT AND IONIC DIFFUSION OF BILE SAlts IN vivo. Passive ionic diffusion of taurocholate and cholate was measured in intestinal segment 2; these flux rates are plotted as a function of the luminal solution concentration of bile salt. The active transport of these bile salts was measured in intestinal segment 9 by correcting the observed flux rates for that net bile salt movement expected on the basis of passive ionic diffusion.

was also considered applicable to distal intestinal segments (line B, Table IV).

In other experiments performed with a luminal solution bile salt concentration of $800 \mathrm{~m} \mu$ moles per $\mathrm{ml}$, the calculated maximal active flux in segment 9 of taurocholate equaled $1,920 \pm 190$ $\mu \mu$ moles per minute per $\mathrm{cm}$ and of cholate equaled $1,900 \pm 87 \mu \mu$ moles per minute per $\mathrm{cm}$; thus in the intact animal the active transport of

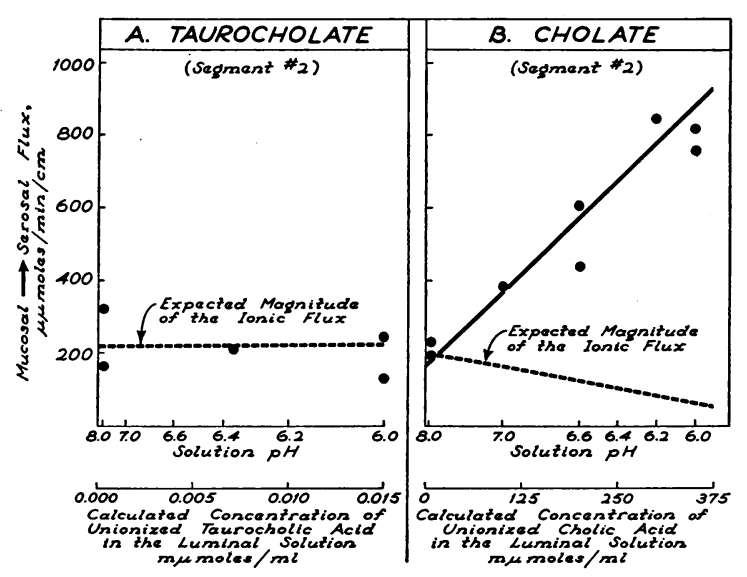

Fig. 8. Nonionic DIFFusion of UN-IONIZED CHOLIC ACID IN vivo. In the second intestinal segment only, mucosal-to-serosal flux rates were determined from luminal solutions of taurocholate or cholate at a concentration of $500 \mathrm{~m} \mu$ moles per $\mathrm{ml}$. These luminal solutions were buffered to $\mathrm{pH}$ values that varied from 6.0 to 8.0 . 
TABLE IV

Magnitude of each of the three processes involved in the in vivo transport of taurocholate and cholate in the proximal jejunum (segment 2) and distal ileum (segment 9)

\begin{tabular}{|c|c|c|c|c|c|}
\hline & & \multicolumn{2}{|c|}{ Taurocholate } & \multicolumn{2}{|c|}{ Cholate } \\
\hline & & Segment 2 & Segment 9 & Segment 2 & Segment 9 \\
\hline (A) & $\begin{array}{l}\text { Active transport maximum, } \\
\mu \mu m o l e s / \mathrm{min} / \mathrm{cm}\end{array}$ & 0 & $1,920 \pm 190$ & 0 & $1,900 \pm 87$ \\
\hline (B) & $\begin{array}{l}\text { Passive ionic diffusion, } \\
\mu \mu m o l e s / \mathrm{min} / \mathrm{cm} / \\
1.0 \mathrm{~m} M \text { gradient }\end{array}$ & $440 \pm 59$ & $440 \pm 59^{*}$ & $400 \pm 80$ & $400 \pm 80^{*}$ \\
\hline (C) & $\begin{array}{l}\text { Passive nonionic diffusion, } \\
\mu \mu m o l e s / \text { min } / \mathrm{cm} / \\
1.0 \mathrm{~m} M \text { gradient }\end{array}$ & 0 & 0 & $2,320 \pm 280$ & $2,320 \pm 280^{*}$ \\
\hline
\end{tabular}

* Assumed to equal that value determined experimentally in segment 2 .

both the conjugated and unconjugated bile salt also occurred at identical rates.

3) Quantification of passive nonionic diffusion. Rate constants for nonionic diffusion of unionized cholic acid under in vivo conditions were obtained by measuring the absorption rates of bile salt at $\mathrm{pH}$ values varying from 6.0 to 8.0 (Figure 8). As shown in line $\mathrm{C}$, Table IV, nonionic diffusion of un-ionized cholic acid occurs at a rate of $2,320 \mu \mu$ moles per minute per $\mathrm{cm}$. This constant is assumed also to be applicable to more distal small intestinal segments.

\section{Discussion}

The results of this study demonstrate that active transport and the passive transport phenomenon of ionic and nonionic diffusion, as well as solvent drag, all play a role in the intestinal absorption of bile salts.

Other investigators $(2,3,5,15-17)$ have shown that only segments taken from the terminal half of the intestine are capable of transporting taurocholate and cholate against concentration gradients. However, it should be emphasized that this observation alone does not constitute proof of active transport. It was possible, for example, that the relatively. low serosal/mucosal ratios that developed for cholate resulted from passive distribution of this negatively charged substance under the influence of the transmural electrical gradient known to exist in the small bowel of the rat (18). If, on the other hand, the much higher ratios found with taurocholate were indeed a manifestation of active transport, it would follow that the active transport carrier is capable of moving the conju- gated but not the unconjugated bile salt against an electrochemical gradient. It therefore became of importance to define precisely the transport characteristics of each of these substances.

Consequently, a series of experiments was undertaken using an in vitro perfusion apparatus (Figure 1) in which the electrochemical gradient across the intestine could be fixed essentially at zero. Under these circumstances the only passive force acting to bring about net movement of bile salt across the intestinal mucosa was solvent drag. Having determined the reflection coefficient for bile salt, we were able to correct the unidirectional flux rates for the effect of bulk water flow. Thus, in this system any deviation of the flux ratio from unity must represent active transport. As shown in Figure 2, the values of the flux ratios were approximately 1.0 for both taurocholate and cholate throughout the proximal small intestine; in contrast, in the distal segments there was, unequivocally, active transport of both the conjugated and unconjugated bile salts. In addition, both the maximal transport velocity and the $\mathrm{K}_{\mathrm{m}}$ for taurocholate and cholate were identical. This result was unexpected in view of the findings in everted gut sacs and strongly implies that the transport carrier does not distinguish between the conjugated and unconjugated forms of this bile salt.

Since conjugation of the cholate moiety with taurine drastically alters the chemical characteristics of the acid side chain, these findings further indicate that this portion of the molecule is not involved in the attachment to the carrier protein. Having localized and defined some of the char- 
acteristics of the active transport system for bile salts, we next undertook studies to evaluate the passive transport phenomena that could also result in the net movement of these acid sterols across the intestinal mucosa. Because of its low pK value, passive movement of taurocholate can only occur through ionic diffusion. Cholate, in contrast, with a $\mathrm{pK}$ of 6.4 , exists in the bowel in both the ionic and un-ionized forms. Hence, passive movement of this unconjugated bile salt can occur both as ionic and nonionic diffusion.

As anticipated, the ionic diffusion of both taurocholate and cholate ions occurred at similar rates for a given concentration gradient (Figure 3), equaling 89 and $83 \mu \mu$ moles per minute per $\mathrm{cm}$ for a $1.0 \mathrm{mM}$ gradient, respectively. The nonionic diffusion of un-ionized cholic acid, on the other hand, occurred at a rate of $610 \mu \mu$ moles per minute per $\mathrm{cm}$ for a $1.0 \mathrm{mM}$ gradient. Thus, for an equal concentration gradient across the bowel wall, the un-ionized acid form of cholate is able to diffuse at a velocity that is over seven times greater than that for the cholate ion.

Everted gut sacs invariably showed much lower serosal/mucosal ratios with cholate than with taurocholate $(3,5)$. These observations have led to the concept that the unconjugated bile salt is not so well transported as the conjugated salt. However, the finding in the present investigation that the active fluxes of taurocholate and cholate are equal when measured directly in the perfusion apparatus clearly is at variance with this concept. This apparent discrepancy can be readily explained by the passive transport processes. As cholate and taurocholate are transported across the everted gut segment, a concentration gradient develops that results in the passive back diffusion of bile salt from the serosal to the mucosal compartment. In addition, a drop in the $\mathrm{pH}$ of the serosal fluid to the range of 6.5 to 7.0 is known to occur. Since the serosal-to-mucosal movement of taurocholate can take place only through ionic diffusion, this flux is relatively small compared to the active mucosal-to-serosal flux; hence, high serosal/mucosal ratios develop. In contrast, serosal-to-mucosal movement of cholate can occur by ionic and, more importantly, by nonionic diffusion; as a consequence of this augmented back diffusion the active mucosal-to-serosal flux can maintain only relatively low serosal/mucosal ratios. When nonionic diffusion of cholate is prevented by buffering the serosal fluid to a $\mathrm{pH}$ of $>7.4$, as shown in Figure 5, serosal/mucosal ratios of cholate can be obtained that are fully as high as those obtained with taurocholate. Clearly, then, the apparent differences in transport of conjugated and unconjugated bile salts found when using the everted gut sac are an artifact of this preparation and not a manifestation of actual differences in the rates of active transport of these two substances.

Similarly, the use of everted gut sacs (or intestinal slices) leads to erroneous values for $V_{\max }$ and $\mathrm{K}_{\mathrm{m}}$ when studying the kinetics of bile salt transport by Lineweaver-Burke plots $(4,5)$. Inherent in this type of investigation is the assumption that changes in the rate of bile salt movement across the gut segment (or into the intestinal slices), brought about by changes in bile salt concentration in the perfusing solution, accurately reflect the first order kinetics of a carrier-mediated transport system. This is certainly not the case in these experimental preparations. As one alters the bile salt concentration, passive as well as active flux rates change; indeed, at high substrate concentrations a major portion of the observed bile salt flux will be due to passive transport phenomena, not to the active transport system that one is attempting to characterize. As a result the slope of the curve in the Lineweaver-Burke plot will be artifactually steepened with a lower intercept on the ordinate and, consequently, an erroneously high value for $V_{\max }$. Since $\mathrm{K}_{\mathrm{m}}$ is equal for $\mathrm{V}_{\max }$ times the slope, the value for the half-maximal concentration will also be considerably higher than the true value. In the present investigation, the use of the in vitro perfusion apparatus allowed direct measurement of the active flux as a function of the bile salt concentration in the perfusing solution under experimental conditions in which bile salt movement due to passive phenomena could be eliminated. Hence, the observed values for $V_{\text {max }}$ and $\mathrm{K}_{\mathrm{m}}$ for cholate and for taurocholate are considerably lower than those previously reported $(4,5)$.

These in vitro experiments, then, established that bile salt absorption could occur by means of active transport or by one of several passive mechanisms including ionic diffusion, nonionic diffusion, and solvent drag. One final transport 


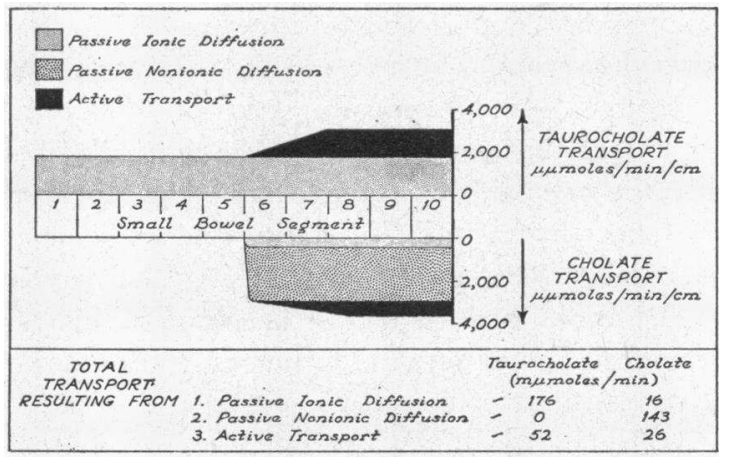

Fig. 9. A SCHEME FOR THE OVER-ALL ABSORPTION OF BILE SALT IN THE RAT INTESTINE. For these calculations, the intraluminal activity of taurocholate was considered to equal 4.0 mmoles per $\mathrm{L}$, whereas the mean activity of cholate in the terminal half of the small bowel was considered equal to 2.0 mmoles per $\mathrm{L}$. The mean $\mathrm{pH}$ of the intraluminal contents was assumed to equal 6.2. Based on these assumptions, the flux rates for each of the transport processes are indicated in the upper panel, and the total transport occurring per minute is indicated in the lower panel.

phenomenon, exchange diffusion, was looked for in ileal segments, but was not observed to occur.

Studies were next undertaken to evaluate the physiologic significance of these in vitro studies by determining the identity and quantitative importance of each of these transport phenomena in the intact animal. Although it was not possible to control rigidly the electrochemical potential across the intestinal mucosa under in vivo conditions, on the basis of the experimental results found in vitro, intestinal segments 2 and 9 were considered representative of areas of the small bowel that either lacked active transport (segment 2 ) or possessed an active transport mechanism for bile salt (segment 9). With these two areas of bowel it was possible to quantitate the rates of active transport and of passive ionic and nonionic diffusion in vivo (Table IV). Although there were quantitative differences between the rate constants for the various active and passive transport mechanisms measured in vitro and in vivo, the relative importance of each was similar in the two experimental situations.

Although these experiments were necessarily designed to allow evaluation of each process individually, under more physiologic conditions the three transport processes must act in concert to bring about net bile salt absorption; furthermore, knowing the bile salt concentration and $\mathrm{pH}$ of the luminal solution, one can predict the net flux on the basis of the rate constants in Table IV. For example, if one places a $1.0 \mathrm{mM}$ cholate solution buffered to $\mathrm{pH} 6.4$ (50\% will be in the un-ionized acid form) in the ileum, on the basis of the in vivo data one would anticipate an active flux of $1,900 \mu \mu$ moles per minute per $\mathrm{cm}$, passive ionic diffusion of $200 \mu \mu$ moles per minute per $\mathrm{cm}$, and passive nonionic diffusion of $1,169 \mu \mu$ moles per minute per $\mathrm{cm}$. The observed total flux in one such experiment was $3,470 \mu \mu$ moles per minute per $\mathrm{cm}$, a value very close to the predicted one of $3,260 \mu \mu$ moles per minute per $\mathrm{cm}$. Similarly, in an experiment in which the rates of absorption. from the proximal small bowel of $1.0 \mathrm{mM}$ solutions of taurocholate and cholate in isotonic saline were compared, values of $390 \mu \mu$ moles per minute per $\mathrm{cm}$ and of 1,680 $\mu$ moles per minute per $\mathrm{cm}$, respectively, were found. Knowing that the $\mathrm{pH}$ of such unbuffered solutions drops to 6.2 in the intestine, one can predict an absorption rate of $440 \mu \mu$ moles per minute per $\mathrm{cm}$ for the conjugated bile salt (ionic diffusion alone) and 1,552 $\mu \mu$ moles per minute per $\mathrm{cm}$ for the unconjugated bile salt (ionic plus nonionic diffusion). Again, there is close agreement between the predicted and experimentally determined flux rates.

With these rate constants, then, as shown in Figure 9, it is possible to formulate an over-all scheme for the absorption of bile salt in the small bowel of the intact animal. For the purposes of these calculations, several assumptions must be made. First, only the reabsorption rates of taurocholate and cholate are taken into account; since over $80 \%$ of the conjugated bile salt in the rat is taurocholate and since cholate is the predominant unconjugated bile salt found in the terminal small intestine, this assumption reasonably approximates the physiologic situation. Second, the intraluminal $\mathrm{pH}$ is considered to equal 6.2 , since unbuffered test solutions placed in the rat intestine invariably fall to this level; similarly, intestinal contents obtained anaerobically from the nonfasting human are found to have $\mathrm{pH}$ values that range from 5.8 to $7.0 .^{\circ}$

Finally, the activity of taurocholate is considered to equal 4 mmoles per $\mathrm{L}$ along the entire length of

6 Performed in conjunction with Dr. John Fordtran. 
the small bowel; cholate is found only in the terminal half of the small intestine, where its mean activity is taken as 2 mmoles per $\mathrm{L}$. The critical micellar concentration (CMC) of taurocholate in an isosmotic electrolyte solution is approximately 5 mmoles per L (19). At concentrations exceeding the CMC, taurocholate exists both as simple molecules in solution-at a concentration that equals the $\mathrm{CMC}$ - and as micelles. There is indirect evidence for the assumption that the activity coefficient $\left(\gamma_{\mathbf{B A}}\right)$ of the bile salt in micellar form is so low that in considerations of membrane transport phenomena, this portion of the taurocholate may be considered totally inactive (20). If one then assumes a value for $\gamma_{\mathbf{B A}}$ for the conjugated bile salt in simple solution of 0.8 (a value similar to that for other strong electrolytes in solutions of this ionic strength), then as long as the total concentration of taurocholate exceeds the CMC, the effective activity of this substance will remain constant at about 4.0 mmoles per L. ${ }^{7}$ Direct measurements in the nonfasting rat show mean cholate concentrations in the terminal half of the small bowel equal to approximately 2.5 mmoles per L; assuming a similar value of 0.8 for the cholate activity coefficient, the mean cholate activity in this area of the intestine will equal approximately 2.0 mmoles per $\mathrm{L}$.

Based on these assumptions, as shown in Figure 9, passive ionic diffusion of taurocholate would occur at every level of the small bowel at a rate of approximately 1,760 $\mu \mu$ moles per minute per $\mathrm{cm}$. In contrast, active bile salt transport would be expected only in the distal segments. Since the transport carrier does not discriminate between the conjugated and unconjugated bile salts, the relative amounts of each of these substances transported will be proportional to their relative activities in the intestinal contents; thus, the active transport rate for taurocholate equals 1,260

${ }^{7}$ In conjunction with other studies, taurocholate and cholate concentrations were determined at all levels of the small bowel by first isolating the individual bile salts by thin layer chromatography, then quantitating them by standard photometric methods (9). By this means taurocholate concentrations were determined to exceed 5 mmoles per $\mathrm{L}$ throughout the length of the small bowel; cholate was not detected in the proximal half of the bowel but was present in an average concentration of nearly 2.5 mmoles per $\mathrm{L}$ in the terminal half of the bowel. $\mu \mu$ moles per minute per $\mathrm{cm}$ and for cholate is 630 $\mu \mu$ moles per minute per $\mathrm{cm}$. At the assumed intraluminal $\mathrm{pH}$ of 6.2 , approximately $61 \%$ of the unconjugated bile salt is present as un-ionized cholic acid; hence, the calculated rate for the nonionic diffusion of this substance equals 2,830 $\mu \mu$ moles per minute per $\mathrm{cm}$, whereas the rate of ionic diffusion for the cholate ion equals only 312 $\mu \mu$ moles per minute per $\mathrm{cm}$.

Assuming that the small intestine of a $220 \mathrm{~g}$ rat is $100 \mathrm{~cm}$ long, the total absorption (in millimicromoles per minute) due to each of these transport processes can be calculated; these data are shown in the lower panel of Figure 9. In this scheme the small intestine would be expected to absorb a total of $413 \mathrm{~m} \mu$ moles of bile salt per minute. From the studies of Eriksson one can estimate that the bile salt pool present in the small intestine of a rat this size varies from 20,300 to $34,400 \mathrm{~m} \mu$ moles (21) ; therefore the small bowel mucosa is potentially able to absorb this total pool of bile salt once every 49 to 90 minutes. By measuring the concentration of bile salt in the portal blood and estimating the portal blood flow, Olivecrona and Sjövall obtained experimental data from which it is possible to calculate that an amount of bile salt equal to the mean small bowel pool is delivered to the liver via the portal vein once every $110 \mathrm{~min}$ utes (22). Thus, there is close agreement between the absorption rate predicted from these theoretical calculations and the value determined experimentally.

This scheme for the transport of bile salt in the intact animal differs considerably from that which has previously been assumed, principally in that passive transport phenomena are assigned a quantitatively important role in the over-all absorption process. It should be emphasized, however, that previous investigators have employed techniques that do not permit the evaluation of passive processes. Of particular interest from a theoretical as well as a clinical point of view is the demonstration that un-ionized cholic acid rapidly penetrates the intestinal mucosa.

In a recent publication Lester and Schmid (23) have reasoned that bilirubin is conjugated in order to prevent its reabsorption from the bowel. A similar teleologic argument may now be applied to the absorption of bile salt, for if the liver secreted free cholic acid rather than the glycine and taurine 
conjugates, then most of this material would be absorbed high in the small bowel by way of nonionic diffusion so that inadequate amounts would be present in the bowel contents to aid in the absorption of dietary fat.

\section{Summary}

In these studies a detailed analysis is made of the various transport phenomena that result in the absorption of bile salt from the small intestine. Under in vitro conditions the active transport of taurocholate and cholate occurs at nearly identical rates equaling $1,380 \pm 350$ and $1,490 \pm 110$ $\mu \mu$ moles per minute per $\mathrm{cm}$, respectively. Similarly, the passive ionic diffusion of taurocholate and cholate ions occurs at similar rates $(89 \pm 12$ and $83 \pm 7 \mu \mu$ moles per minute per $\mathrm{cm}$ for a 1.0 $\mathrm{mM}$ gradient), whereas at the physiologic $\mathrm{pH}$ values found in the intestine only un-ionized cholic acid penetrates the intestinal mucosa by way of nonionic diffusion $(610 \pm 95 \mu \mu$ moles per minute per $\mathrm{cm}$ for a $1.0 \mathrm{mM}$ gradient).

In the intact animal similar transport mechanisms were identified and quantitated. The maximal transport rate in vivo for taurocholate is $1,920 \pm 190 \mu \mu$ moles per minute per $\mathrm{cm}$ and for cholate equals $1,900 \pm 87 \mu \mu$ moles per minute per $\mathrm{cm}$. Passive ionic diffusion of both the conjugated and unconjugated bile salts occurs at the nearly equal rates of $440 \pm 59$ and $400 \pm 80 \mu \mu$ moles per minute per $\mathrm{cm}$ for a $1.0 \mathrm{mM}$ gradient, respectively, whereas nonionic diffusion of un-ionized cholic acid takes place at a rate of $2,320 \pm 280$ $\mu \mu$ moles per minute per $\mathrm{cm}$. The quantitative importance of each of these phenomena in the overall process for the absorption of bile salt is discussed.

\section{References}

1. Hofmann, A. F., and B. Borgström. Physico-chemical state of lipids in intestinal contents during their digestion and absorption. Fed. Proc. 1962, 21, 43.

2. Baker, R. D., and G. W. Searle. Bile salt absorption at various levels of rat small intestine. Proc. Soc. exp. Biol. (N. Y.) 1960, 105, 521.

3. Lack, L., and I. M. Weiner. In vitro absorption of bile salts by small intestine of rats and guinea pigs. Amer. J. Physiol. 1961, 200, 313.

4. Holt, P. R. Intestinal absorption of bile salts in the rat. Amer. J. Physiol. 1964, 207, 1.
5. Playoust, M. R., and K. J. Isselbacher. Studies on the transport and metabolism of conjugated bile salts by intestinal mucosa. J. clin. Invest. 1964, 43, 467.

6. Hofmann, A. F. Thin-layer adsorption chromatography of free and conjugated bile acids on silicic acid. J. Lipid Res. 1962, 3, 127.

7. Umbreit, W. W., R. H. Burris, and J. F. Stauffer. Manometric Techniques, 3rd ed. Minneapolis, Burgess, 1957, p. 149.

8. Wilson, T. H., and G. Wiseman. The use of sacs of everted small intestine for the study of the transference of substances from the mucosal to the serosal surface. J. Physiol. (Lond.) 1954, 123, 116.

9. Irvin, J. L., C. G. Johnston, and J. Kopala. A photometric method for the determination of cholates in bile and blood. J. biol. Chem. 1944, 153, 439.

10. Dietschy, J. M. Water and solute movement across the wall of the everted rabbit gall bladder. Gastroenterology 1964, 47, 395.

11. Bray, G. A. A simple efficient liquid scintillator for counting aqueous solutions in a liquid scintillation counter. Analyt. Biochem. 1960, 1, 279.

12. Okita, G. T., J. J. Kabara, F. Richardson, and G. V. LeRoy. Assaying compounds containing $\mathrm{H}^{3}$ and $C^{14}$. Nucleonics 1957, 15, 111.

13. Leaf, A., and R. M. Hays. Permeability of the isolated toad bladder to solutes and its modification by vasopressin. J. gen. Physiol. 1962, 45, 921.

14. Ussing, H. H. The Alkali Metal Ions in Biology. Berlin, Springer-Verlag, 1960.

15. Weiner, I. M., and L. Lack. Absorption of bile salts from the small intestine in vivo. Amer. J. Physiol. 1962, 202, 155.

16. Tidball, C. S. Intestinal and hepatic transport of cholate and organic dyes. Amer. J. Physiol. 1964, 206, 239.

17. Glasser, J. E., I. M. Weiner, and L. Lack. Comparative physiology of intestinal taurocholate transport. Amer. J. Physiol. 1965, 208, 359.

18. Clarkson, T. W., A. C. Cross, and S. R. Toole. Electrical potentials across isolated small intestine of the rat. Amer. J. Physiol. 1961, 200, 1233.

19. Hoffmann, A. F. Micellar solubilization of fatty acids and monoglycerides in bile salt solutions in Enzymes of Lipid Metabolism. New York, Pergamon, 1961.

20. Moore, E. W., and J. M. Dietschy. Na and K activity coefficients in bile and bile salts determined by glass electrodes. Amer. J. Physiol. 1964, 206, 1111.

21. Eriksson, S. Bile acid pool in the rat. Acta physiol. scand. 1960, 48, 439.

22. Olivecrona, T., and J. Sjövall. Bile acids in rat portal blood. Acta physiol. scand. 1959, 46, 284.

23. Lester, R., and R. Schmid. Intestinal absorption of bile pigments. I. The enterohepatic circulation of bilirubin in the rat. J. clin. Invest. 1963, 42, 736. 